\title{
Ultraviolet degradation of methyltins: Elucidating the mechanism by identification of a detected new intermediary product and investigating the kinetics at various environmental conditions
}

\author{
Guangshu Zhai, Jingfu Liu, Bin He, Jianbin Zhang, Qunfang Zhou, Guibin Jiang* \\ State Key Laboratory of Environmental Chemistry and Ecotoxicology, Research Center for Eco-Environmental Sciences, \\ Chinese Academy of Sciences, P.O. Box 2871, Beijing 100085, China
}

Received 10 November 2007; received in revised form 19 February 2008; accepted 19 February 2008

Available online 22 April 2008

\begin{abstract}
The photodegradation of methyltins, as environmental pollutants, has scarcely been studied so far because of the shortage of rapid and sensitive speciation methods, even though they have very simple structures. The photodegradation of monomethyltin trichloride (MMT), dimethyltin dichloride (DMT) and trimethyltin chloride (TMT) was studied with our new developed HPLC-FPD hyphenated system, which enables rapid and sensitive detection of methyltins. The half-life times and kinetic rate constants of their degradation at different $\mathrm{pH}$ were calculated. The results suggest that MMT, DMT and TMT can be degraded under the UV irradiation rapidly at different $\mathrm{pH}$, with a degradation rate sequence of TMT $<$ DMT $<$ MMT. An unknown intermediary product, which is more stable and has higher concentration at $\mathrm{pH} 8$ for MMT and DMT, of methyltin photodegradation was detected for the first time. This unknown intermediary product was identified as methyloltin with electrospray mass spectrometry, and the possible mechanism was proposed based on the intermediary product. The effects of some environmental parameters such as salinity and humic acid on the degradation rate of methyltins were also investigated. Results suggest that salinity and humic acid have strong effect on their degradation, especially for TMT, which was almost never degraded in the solutions containing $\mathrm{NaCl}$ and humic acid.
\end{abstract}

(C) 2008 Elsevier Ltd. All rights reserved.

Keywords: Ultraviolet degradation; Methyltin; Reaction intermediates; Mechanism; Kinetics

\section{Introduction}

Organotin compounds are omnipresent in the environment (Burton et al., 2006; Rüdel et al., 2007; Gómez-Ariza et al., 2006) because of their extensive applications as biocides, antifouling agents and polyvinyl chloride heater stabilizers over the past decades. Although their uses have been banned by many countries (Fent, 1996), some organotin compounds such as methyltin compounds continue to be produced and used as polymer stabilizers nowadays. On the other hand, unlike the other organotin compounds that

\footnotetext{
* Corresponding author. Tel.: +86 10 62849334; fax: +86 1062849179 . E-mail address: gbjiang@rcees.ac.cn (G. Jiang).
}

might disappear following the prohibited use, the methyltin compounds will exist in the environment for a long time because of biotic and abiotic tin methylation (Ashby and Craig, 1988). Generally, the shorter chain of alkyl groups, the higher toxicity of the organotins. For methyltins, the toxicity follows the sequence: trimethyltin (>tetramethyltin) $>$ dimethyltin $>$ methyltin (Pettibone and Cooney, 1988). For example, methyltins, especially trimethyltin, demonstrate more toxic to fungi and insects than other organotin compounds (Ebdon et al., 1998).

Due to the high toxicity of organotin compounds, their fate in the environment (biotic and abiotic degradation) is an important issue in the study of their environmental behavior (Burton et al., 2005; Lee et al., 2006). The disappearance of organotins from the environment is mainly 
attributed to their biodegradation, photolysis and chemical degradation. They can be degraded through stepwise dealkylation to form inorganic tin under various environmental conditions. The biodegradation of organotin compounds, such as degradation by bacteria (Harinoa et al., 1997; Inoue et al., 2000), has been studied in detail. The abiotic degradation mainly includes the gamma irradiation (Allen et al., 1987) and photolysis (Maguire et al., 1983; Blunden, 1983; Mailhot et al., 1999). Some investigations have been conducted to study the process of photodegradation of organotin compounds because photolysis is an important process for organotin compounds in the environment. But these studies mainly focus on the degradation of butyltin and phenyltin compounds rather than methyltins. Mailhot et al. (1999) investigated the iron (III) photoinduced degradation of tributyltin chloride (TBT). They proved that the degradation of TBT is due to the attack of $\mathrm{OH}$ radicals, and the main route to degradation is a stepwise debutylation of TBT to di- and mono-butyltin with final formation of inorganic tin. In order to accelerate the degradation rate in aqueous solution, $\mathrm{TiO}_{2}$ was used for photocatalytic degradation of butyltin compounds under UV illumination (Navio et al., 1996). The photodegradation of triphenyltin in water was also studied (Soderquist and Crosby, 1978, 1980).

The degradation kinetics and mechanism of methyltin compounds, including photodegradation, was scarcely studied. Blunden (1983) studied the ultraviolet degradation of methyltin chlorides in carbon tetrachloride and water using NMR technique, but the adopted concentration of these methyltin compounds was $0.05 \mathrm{M}$ (as $\mathrm{Sn}$ ), which is $5935 \mathrm{mg}^{-1}$ (as Sn) and far higher than their real concentration in environment. One of the main reasons for the scarce research on the degradation of methyltins is the shortage of a rapid and sensitive method for the speciation of methyltin compounds. Gas chromatography (GC) and high performance liquid chromatography (HPLC) based hyphenated techniques, such as GC-AAS (atomic absorption spectrometry) (Ritsema, 1992) and GC-ICP-MS (inductively-coupled plasma mass spectrometry) (Tao et al., 1999) are the general methods to determine methyltin compounds. The complicated pretreatment step (Pellegrino et al., 2000) and derivatization step (Morabito and Massanisso, 2000) in GC methods limited their applications in the study of methyltin degradation because a large number of samples during degradation process have to be analyzed rapidly in $30 \mathrm{~min}$. For the HPLC methods, the difficulties originate mainly from the scarce of sensitive detector to measure methyltin compounds. Though ICPMS (Chao and Jiang, 1998) is a sensitive detector for methyltin compounds, it is difficult to couple it with reversed phase-HPLC for the speciation of methyltins because of its incompatibility with the higher content of organic solvents (methanol or acetonitrile) that have to be used to separate methyltins. High levels of organic solvents in the mobile phase of reversed phase liquid chromatography causes the extinction of ICP which restricts the applications of ICP-MS hyphenated with reversed phase HPLC. Recently, we have developed a HPLC-HG-MGLS-QSILFPD (HPLC-hydride generation-microporous membrane gas-liquid separator-quartz surface-induced luminescence flame photometric detector) system for convenient speciation of methyltin compounds with high sensitivity and efficiency (Zhai et al., 2007).

In this work, the degradation kinetics and mechanism of methyltins under the UV irradiation was studied with the new developed HPLC-HG-MGLS-QSIL-FPD method, and the newly detected intermediary product was confirmed using ESI-Q-TOF-MS. The influenced mechanisms of some environmentally relevant parameters such as $\mathrm{pH}$, salinity and humic acid on the degradation of methyltins were studied in detail.

\section{Materials and methods}

\subsection{Chemicals and reagents}

All reagents were used as purchased without further purification. Three methyltin compounds, including trimethyltin chloride (TMT, 98\%), dimethyltin dichloride (DMT, 97\%) and monomethyltin trichloride (MMT, 97\%), were obtained from Aldrich Chemical Co. (USA). Standard stock solutions were prepared by dissolving methyltin compounds in deionized water and stored at $4{ }^{\circ} \mathrm{C}$. The working solutions were prepared daily by appropriate diluting the stock solutions with water and adjust to pH 3.5 using hydrochloric acid. Methanol was HPLC grade solvent (J.T. Baker, Phillipsburg, NJ, USA). Tropolone $(98 \%)$ and humic acid (sodium salt, tech. $50-60 \%$ as humic acid) were purchased from Acros Organics (NJ, USA). The $600 \mathrm{mg}^{-1}$ humic acid as stock solution in the experiments was filtered using $0.45 \mu \mathrm{m}$ membrane. Acetic acid (AR, 99.5\%), hydrochloric acid (AR, 36-38\%), sodium chloride, (AR, 99.5\%), potassium hydroxide (GR) and anhydrous calcium chloride were obtained from Beijing Chemical Factory (Beijing, China). Potassium borohydride ( $>95 \%)$ was purchased from Institute of Geophysical and Geochemical Exploration (Langfang, China). The deionized water $(18.3 \mathrm{M} \Omega)$ was from an ultrapure water system (Barnstead International, Dubuque, IA, USA).

\subsection{Apparatus}

The hyphenated HPLC-HG-MGLS-QSIL-PFD system was the same as described previously (Zhai et al., 2007). In brevity, methytin compounds were at first separated by the HPLC system which consists of a DGU-12A degasser, a LC-10A pump (Shimdzu, Japan), an injector valve (Rheodyne $7725 i$ with a $200 \mu 1$ sample loop), and a $\mathrm{C}_{18}$ separation column (Agilent Zorbax Eclipse XDB-C18, $5 \mu \mathrm{m}$ particle size, $4.6 \times 150 \mathrm{~mm}$ ). The analytes from the HPLC column reacted with the derivatization reagents to form volatile methyltin hydride. These volatile methyltin hydride compounds were separated from the liquid matrix with a 
microporous membrane gas-liquid separator (MGLS). When the volatile methyltin hydride compounds pass through the gas-liquid mixture channel of the MGSL, they diffused through the micropores of the PTFE membrane into the gas channel and were transported to the dryer by the high-purity nitrogen from GC injector used as carrier gas. After dried by the anhydrous calcium chloride in the dryer, the methyltin hydride compounds were introduced into the QSIL-FPD for detection. The QSIL-FPD was installed on a gas chromatography (BeiFen-3420, China) with BF-2002 chromatographic workstation software. The operating conditions of this hyphenated system are displayed in Table S1 (see supplementary material).

Macromass Electrospray ionization-Quadrupole-Time of flight-mass spectrometry (ESI-Q-TOF-MS) with Masslynx 4.1 workstation software was from Waters Company. The major voltage conditions are listed as follows: negative ionisation mode $\left(\mathrm{ESI}^{-}\right), 2500.0 \mathrm{~V}$ capillary, $30.0 \mathrm{~V}$ sample cone, $2.0 \mathrm{~V}$ extraction cone, $1.0 \mathrm{~V}$ ion energy, $5.0 \mathrm{~V}$ collision energy, $5630.0 \mathrm{~V}$ TOF flight tube and $1780.0 \mathrm{~V}$ reflectron. The high-pure nitrogen is as the carrier gas with flow rate of cone of $501 \mathrm{~h}^{-1}$ and desolvation of $3501 \mathrm{~h}^{-1}$. The temperatures of desolvation and source are 150.0 and
$80.0{ }^{\circ} \mathrm{C}$, respectively. The syringe rate is $30.0 \mu \mathrm{min}^{-1}$ and the scan mass range is from $m / z 100$ to 500 .

The ultraviolet light (UV) source for photodegradation is a $40 \mathrm{~W}$ low-pressure mercury vapor lamp with the wave length of emission of $253.7 \mathrm{~nm}$ and lamp length of $38 \mathrm{~cm}$.

\subsection{Procedure}

Into a $250 \mathrm{ml}$ beaker was added $200 \mathrm{ml}$ of $500 \mathrm{ng} \mathrm{ml}^{-1}$ (as Sn) MMT, DMT or TMT solution, and the UV lamp was adjusted to $6 \mathrm{~cm}$ over the liquid surface of beaker. Typically, four samples can be simultaneously processed. After irradiation for the prescribed time with the UV lamp, $200 \mu \mathrm{l}$ of the sample solution was taken from the beaker and directly injected into HPLC-HG-MGLS-QSIL-PFD system, and the methyltin compounds can be completely separated and determined within $20 \mathrm{~min}$. To investigate the effect of $\mathrm{pH}$, methyltin solutions was adjusted to $\mathrm{pH}$ 4, 6 and 8, using hydrochloric acid and potassium hydroxide. Methyltin solutions with $0,0.5,1.5$ and $3.0 \%(\mathrm{~m} / \mathrm{v})$ of sodium chloride and $\mathrm{pH} 6$ were used to study the effect of salinity, and solutions with $0,3,6$ and $9 \mathrm{mg}^{-1}$ of humic
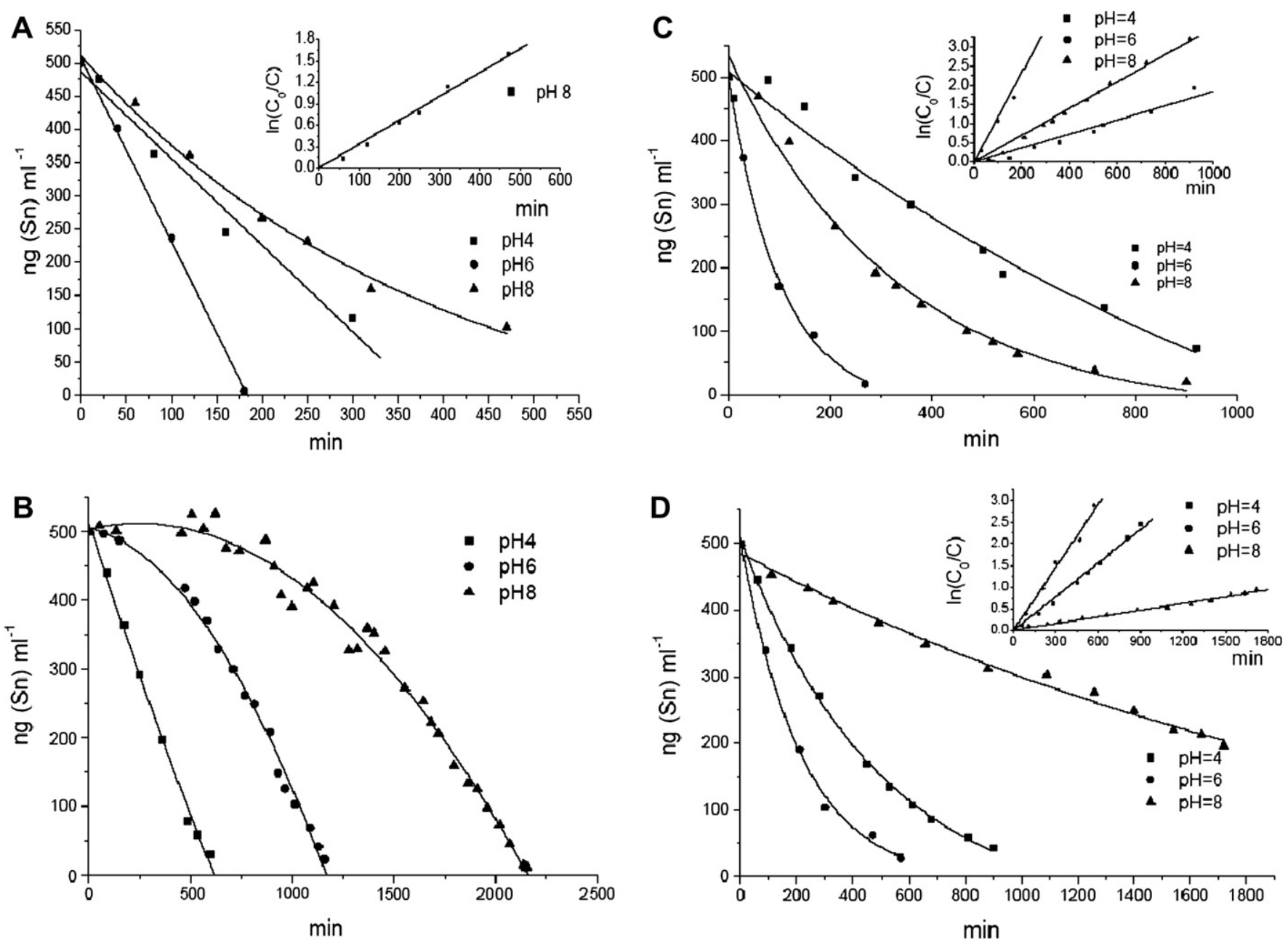

Fig. 1. Effect of $\mathrm{pH}$ on the photodegradation rates of methyltins. (A) MMT, (B) MMT containing $0.05 \%$ methanol (v/v), (C) DMT, and (D) TMT. 
acid and $\mathrm{pH} 6$ were used to evaluate the effect of humic acid.

\section{Results and discussion}

\subsection{Degradation kinetics at different $p H$}

The methyltin compounds can be degraded under the irradiation of ultraviolet light. As can be seen from Fig. 1, the degradation rates of MMT, DMT and TMT is strongly dependent on the solution $\mathrm{pH}$. All the degradation curves of methyltins are in accord with the pseudo-first-order rate equation except for the MMT at $\mathrm{pH} 4$ and 6, which are in accord with zero-order rate equation (see Table $\mathrm{S} 2$ in supplementary material). For all the studied methyltins the highest degradation rate was obtained at $\mathrm{pH} 6$, while the lowest one was obtained at $\mathrm{pH} 8$. Two major reasons might be responsible for this phenomenon. First, the species of the three methyltin compounds in water are dependent on the $\mathrm{pH}$, which influences the energy needed to break the Sn-C bond. Various species of methyltin cations are formed over a wide $\mathrm{pH}$ range (Stefano et al., 1999). For example, $\left(\mathrm{CH}_{3}\right)_{2} \mathrm{Sn}^{2+}$ forms five species including $\left(\mathrm{CH}_{3}\right)_{2} \mathrm{Sn}(\mathrm{OH})^{+}$, $\left(\mathrm{CH}_{3}\right)_{2} \mathrm{Sn}(\mathrm{OH})_{2}^{0}, \quad\left(\mathrm{CH}_{3}\right)_{2} \mathrm{Sn}(\mathrm{OH})_{3}^{-}, \quad\left[\left(\mathrm{CH}_{3}\right)_{2} \mathrm{Sn}\right]_{2}(\mathrm{OH})_{2}^{2+}$ and $\left[\left(\mathrm{CH}_{3}\right)_{2} \mathrm{Sn}\right]_{2}(\mathrm{OH})_{3}^{+}$, while $\left(\mathrm{CH}_{3}\right)_{3} \mathrm{Sn}^{+}$forms only $\left(\mathrm{CH}_{3}\right)_{3} \mathrm{Sn}(\mathrm{OH})^{0}$ and $\left(\mathrm{CH}_{3}\right)_{3} \mathrm{Sn}(\mathrm{OH})_{2}^{-}$. Monomethyltin(IV) cation undergoes hydrolysis and forms $\mathrm{CH}_{3} \mathrm{Sn}(\mathrm{OH})_{2}^{+}$, $\mathrm{CH}_{3} \mathrm{Sn}(\mathrm{OH})_{3}^{0}$ and $\mathrm{CH}_{3} \mathrm{Sn}(\mathrm{OH})_{4}^{-}$species in the $\mathrm{pH}$ range $2-10.5$. Moreover, the species would be hydrated to form more stable structures with a coordination number of 5 or 6. Second, the UV degradation of organic compounds is the free radical reaction, which is influenced by the various anions in aqueous solutions. For example, the degradation rate of 4-chlorophenol (Lipczynska-Kochany et al., 1995) in aqueous solutions was found to decrease with the following sequence: $\mathrm{ClO}_{4}^{-} \sim \mathrm{NO}_{3}^{-}>\mathrm{SO}_{4}^{2-}>\mathrm{Cl}^{-} \gg \mathrm{HPO}_{4}^{2-}>\mathrm{HCO}_{3}^{-}$, since these anion can scavenge the hydroxyl radical in the reactions. As an anion, $\mathrm{OH}^{-}$can also function as a free radical scavenger in aqueous solutions, it can inhibit and reduce the formation of hydroxyl radical thus decrease the degradation rate of methyltins at $\mathrm{pH} 8$. Since $\mathrm{HCl}$ was used to adjust the solution $\mathrm{pH}$, the aqueous solutions at
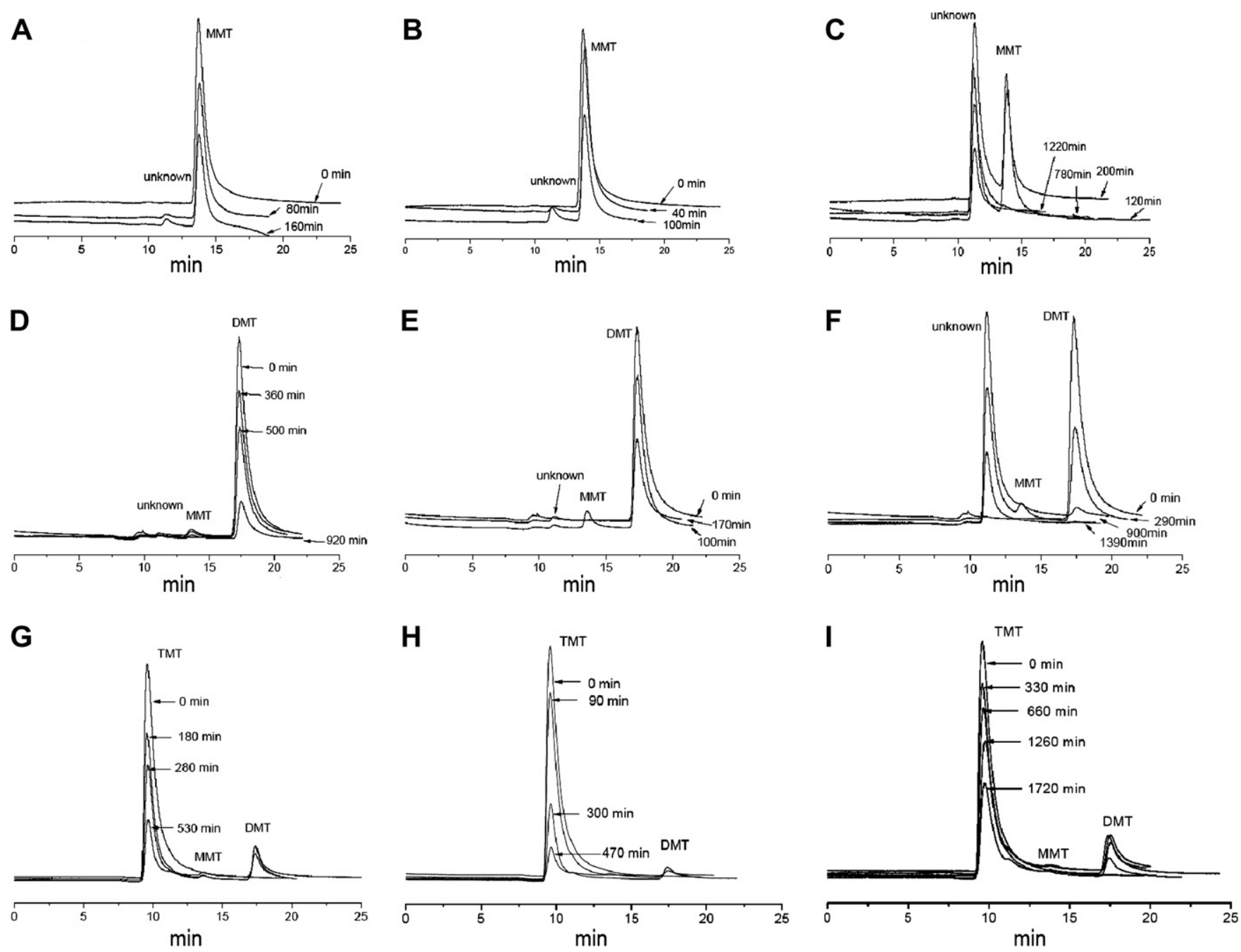

Fig. 2. Some typical chromatograms of photodegradation of methyltins at the different reaction times. (A) MMT at pH 4, (B) MMT at pH 6, (C) MMT at $\mathrm{pH} 8$, (D) DMT at pH 4, (E) DMT at pH 6, (F) DMT at pH 8, (G) TMT at pH 4, (H) TMT at pH 6, and (I) TMT at pH 8. 
$\mathrm{pH} 4$ possessed higher concentration of $\mathrm{Cl}^{-}$than that at $\mathrm{pH}$ 6 and thus lower degradation rate. Similar results were obtained in the degradation of trichloroethylene (TCE) with persulfate oxidation (Liang et al., 2007). The maximum degradation rate of TCE occurred at $\mathrm{pH} 7$, while the degradation rate decreased with either an increase or a decrease of $\mathrm{pH}$ within $\mathrm{pH} 4-9$ as $\mathrm{SO}_{4}^{2-}$ may play a role in scavenging hydroxyl radical and thus slowing down the TCE degradation rate.

As shown in Fig. 1 and Table S2, the degradation rate of methyltins has a sequence of TMT $<$ DMT $<$ MMT because of the reverse sequence of methyl groups which hinder the reaction. However, Blunden (1983) observed a degradation rate sequence of TMT $>$ DMT $>$ MMT, which probably is due to the adopted concentration of methyltins and the energy of UV lamp are different from this study. Another reason is that the NMR technique used by Blunden cannot distinguish the signals of the MMT and the intermediate product, which have very similar structure. Our study indicates that the degradation route of methyltins might be a stepwise demethylation to inorganic tin, as the detected degradation products were DMT, MMT and an unknown intermediate product for TMT; MMT and the unknown intermediate product for DMT; as well as only the unknown intermediate product for MMT, respectively. However, Blunden (1983) did not detect MMT during the TMT degradation process, which might be attributed to the low sensitivity of NMR spectroscopy as very low concentration of MMT was detected during the degradation process of DMT and TMT at $\mathrm{pH} 6$ in this study. High concentration of the intermediate product was formed for MMT and DMT at $\mathrm{pH} 8$, which means that the intermediate product can be easily formed at $\mathrm{pH}$ 8; whereas DMT degraded to MMT, then form the intermediate product and finally tin. For TMT, however, the degradation mechanism might be different from that of MMT and TMT as the intermediate product was not detected even at $\mathrm{pH}$ 8. The possible degradation mechanisms of methyltins and the confirmation of the intermediate product will be discussed later.

To prove the degradation to take place through the radical reaction, methanol $(0.05 \%, \mathrm{v} / \mathrm{v})$, a well-known hydroxyl radical scavenger (Marugan et al., 2006), was added to the MMT aqueous solution. It can be seen from Fig. 1B that methanol greatly inhibits the degradation of MMT at all the studied $\mathrm{pH}$ values. The half-life time at $\mathrm{pH} \mathrm{4,6}$ and 8 increased from 181, 93 and $210 \mathrm{~min}$ to 305,815 and $1645 \mathrm{~min}$, respectively (Table S2, supplementary material). Therefore, it can be concluded that the degradation of methyltins under the UV irradiation is through the radical reaction.

\subsection{Confirmation of the unknown intermediary product}

It is very important to elucidate the structure of the intermediate product to understand the mechanism of methyltin degradation. According to the chromatograms of methyltins (Fig. 2), the retention times of TMT, MMT, DMT and the intermediate product are 9.6, 13.7, 17.3 and $11.2 \mathrm{~min}$, respectively. Because MMT, DMT and TMT have the same intermediate product and MMT has the simplest structure, MMT was used to deduce the structure of the intermediate product. Fig. 3 shows that the peak height of the intermediate product increases at first and then decreases during the degradation process of MMT, which means that the intermediate product is an organotin compound because organotin compounds have higher sensitivity using the sulfur interference filter $(390 \mathrm{~nm})$ in this study. However, the maximum emission wavelength of $\mathrm{Sn}-\mathrm{H}$ bonds is at $610 \mathrm{~nm}$ (Dagnall et al., 1968) and the sensitivity of FPD for inorganic tin is poor at $390 \mathrm{~nm}$, even no signal for the end product, inorganic tin. The retention time of the intermediate product is shorter than that of MMT in the reversed phase HPLC chromatogram, suggesting that the polarity of the
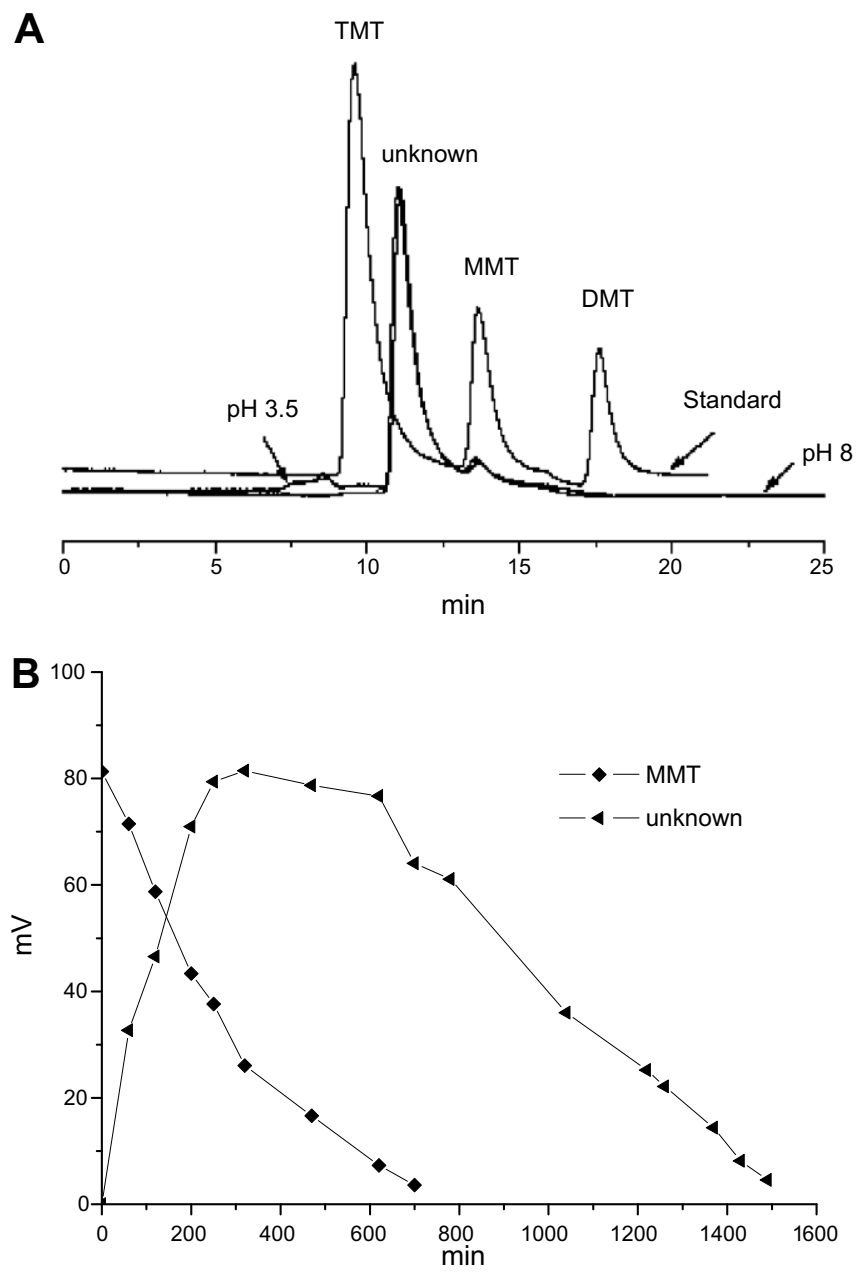

Fig. 3. Comparison of the unknown intermediate product and methyltin standards: (A) unknown intermediate product taken from almost completely degraded MMT and the unknown intermediate product having higher peak height shown in $\mathrm{B}$ at $\mathrm{pH} 3.5$ and 8 , (B) variation of the concentrations of MMT and the unknown intermediate product during the degradation process. 

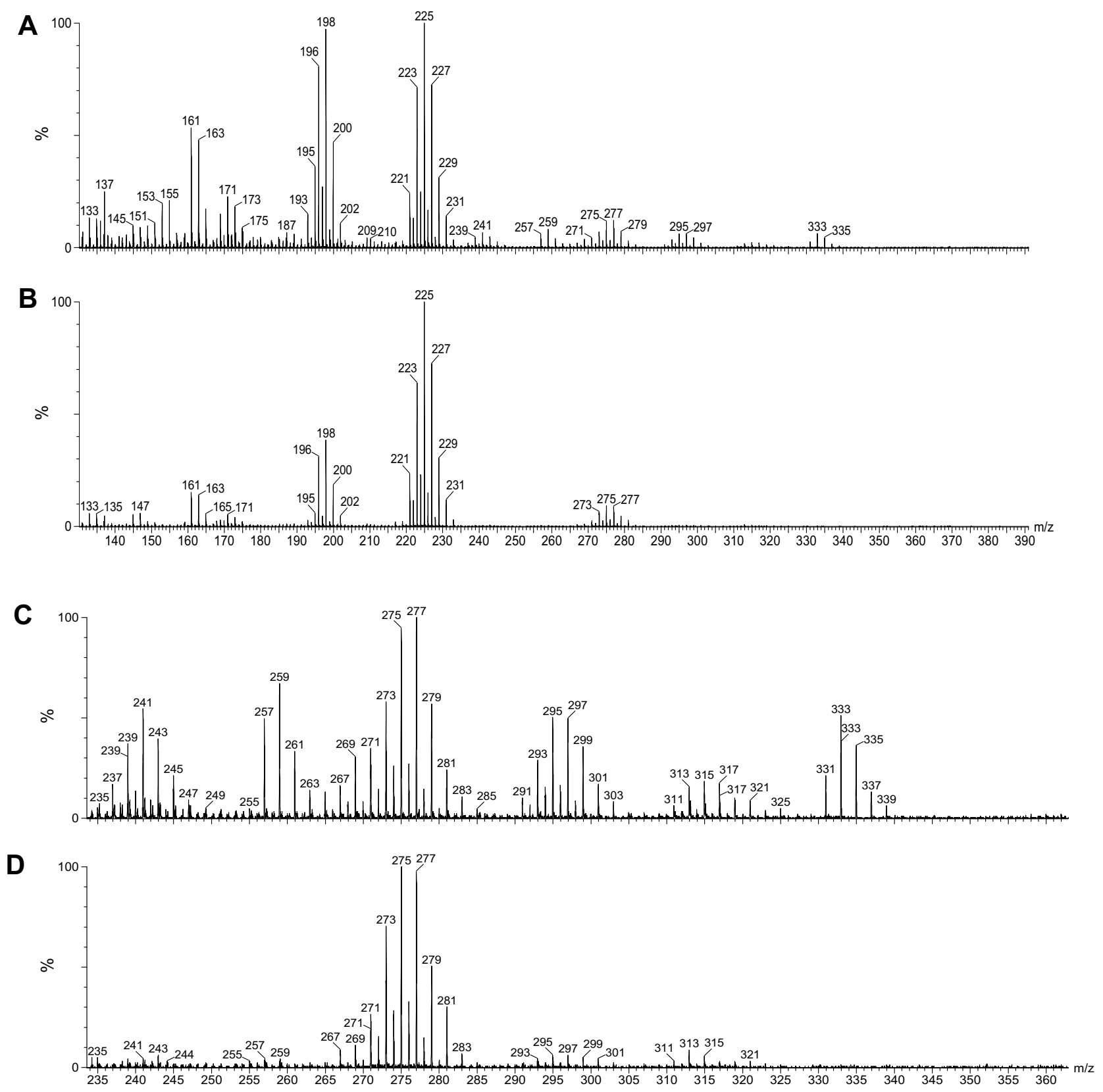

Fig. 4. Spectra of MMT and the intermediate product using ESI- ${ }^{-}$- - TOF-MS. (A) the intermediate product, (B) standard MMT, (C) and (D) are the magnification spectra of (A) and (B) from $\mathrm{m} / z 235$ to 360 .

Table 1

Ions observed in the negative ESI mass spectra of MMT and the intermediate organotin compound and their structures

Major ion $(\mathrm{m} / \mathrm{z})$ and structure

MMT $\quad$ Intermediate product: $\left(\mathrm{CH}_{2} \mathrm{OH}\right) \mathrm{Sn}^{3+}$

$221,223,225,227,229,231$

$\left[\mathrm{Sn}(\mathrm{OH})_{4} \mathrm{Cl}\right]^{-}$

$271,273,275,277,279,281$

$\left[\mathrm{Sn}\left(\mathrm{CH}_{3}\right) \mathrm{Cl}_{4}\right]^{-}$
$221,223,225,227,229,231$

$239,241,243,245$

$257,259,261,263$

271, 273, 275,277, 279, 281

293, 295, 297,

299, 301

$313,315,317,319$

$331,333,335,337$
$\left[\mathrm{Sn}(\mathrm{OH})_{4} \mathrm{Cl}\right]^{-}$

$\left[\mathrm{Sn}\left(\mathrm{CH}_{2} \mathrm{OH}\right)(\mathrm{OH})_{3} \mathrm{Cl}\right]^{-}$

$\left[\mathrm{Sn}\left(\mathrm{CH}_{2} \mathrm{OH}\right)(\mathrm{OH})_{2} \mathrm{Cl}_{2}\right]^{-}$

$\left[\mathrm{Sn}\left(\mathrm{CH}_{2} \mathrm{OH}\right)(\mathrm{OH}) \mathrm{Cl}_{3}\right]^{-}$

$\left[\mathrm{Sn}\left(\mathrm{CH}_{2} \mathrm{OH}\right) \mathrm{Cl}_{4}\right]^{-}$

$\left[\mathrm{Sn}\left(\mathrm{CH}_{2} \mathrm{OH}\right) \mathrm{Cl}_{4}\left(\mathrm{H}_{2} \mathrm{O}\right)\right]^{-}$ $\left[\mathrm{Sn}\left(\mathrm{CH}_{2} \mathrm{OH}\right) \mathrm{Cl}_{4}\left(\mathrm{H}_{2} \mathrm{O}\right)_{2}\right]^{-}$ 
intermediate product is stronger than that of MMT. Thus, the intermediate product might be $\mathrm{CH}_{2} \mathrm{OH}-\mathrm{Sn}^{3+}$, (CHO)$\mathrm{Sn}^{3+}$ or $\mathrm{CH}_{3} \mathrm{O}-\mathrm{Sn}^{3+}$. As $\mathrm{Sn}-\mathrm{C}$ bond is detected at $390 \mathrm{~nm}$ (Aue and Flinn, 1977) by QSIL-FPD, the intermediate product should not be $\mathrm{CH}_{3} \mathrm{O}-\mathrm{Sn}^{3+}$. During the degradation process, the amount of the formed intermediate product was strongly dependent on the solution $\mathrm{pH}$ because its content at $\mathrm{pH} 8$ is greatly higher than that at $\mathrm{pH} 4$ and 6 . This suggests that this intermediate product is easier formed and more stable at alkaline solutions, thus methyloltin compound $\left(\mathrm{CH}_{2} \mathrm{OH}-\mathrm{Sn}^{3+}\right)$ has higher possibility. To detect the intermediate product and thus elucidate its structure, direct electrospray ionization-Quadrupole-Time of flight-mass spectrometry (ESI-Q-TOF-MS) was used to determine the samples taken from a completely degradraded MMT solution which had a higher concentration of the intermediate product (Fig. 3B). The result suggests the intermediate product at $\mathrm{pH} 3.5$ and 8 has equal stability as the same peak height and retention time were obtained from the chromatograms shown in Fig. 3. Therefore, the structure of intermediate product was elucidated at $\mathrm{pH}$ 3.5 in order to get stronger signal using ESI-Q-TOF-MS. Electrospray ionization (ESI) is one of the softest ionization techniques, which enables the determination of molecular weight of many organometallic, especially organotin compounds (Rosenberg et al., 2000; Rosenberg, 2003; Apek et al., 2006). Both the positive and negative ionization modes were investigated by ESI-Q-TOF-MS, and results suggested the negative mode has stronger signals than the positive mode (data no shown). Moreover, experiment shows that, with negative ionization mode, better signal was obtained at $\mathrm{pH} 3.5$ than at $\mathrm{pH} 8$ as organotin compounds are easier to complex with $\mathrm{Cl}^{-}$at $\mathrm{pH} 3.5$ to produce the a series of charged species. In fact, the detection of a number of charged organotin species is one of the characteristics of electrospray mass spectrometry, which was applied in identification of reaction products organotin compounds $\mathrm{R}_{3} \mathrm{SnCl}(\mathrm{R}=\mathrm{Ph}, \mathrm{Me}$ or $\mathrm{Bu})$ by negative mode (Henderson and Taylor, 1996). Solutions of $\mathrm{Ph}_{3} \mathrm{SnX}(\mathrm{X}=\mathrm{Cl}$ or $\mathrm{Br})$ yields $\left[\mathrm{Ph}_{3} \mathrm{SnX}_{2}\right]^{-},\left[\mathrm{Ph}_{3} \mathrm{SnX}(\mathrm{OH})\right]^{-}$, $\left[\mathrm{Ph}_{3} \mathrm{SnO}\right]^{-}$and $\left[\mathrm{Ph}_{3} \mathrm{SnOSnPh}_{3} \mathrm{X}\right]^{-}, \mathrm{Me}_{3} \mathrm{SnCl}$ yields $\left[\mathrm{Me}_{3^{-}}\right.$ $\left.\mathrm{SnCl}_{2}\right]^{-}$and $\left[\mathrm{Me}_{3} \mathrm{SnOSnMe}_{3}(\mathrm{OH})\right]^{-}$, whereas $\mathrm{Bu}_{3} \mathrm{SnCl}$ gives $\left[\mathrm{Bu}_{3} \mathrm{SnCl}_{2}\right]^{-}$and $\left[\mathrm{Bu}_{3} \mathrm{SnCl}(\mathrm{OH})\right]^{-}$. Various charged species were also detected in this study with negative ESIQ-TOF-MS at pH 3.5 (Fig. 4 and Table 1). It can be seen from Fig. 4 that MMT and the intermediate product exhibited stronger signals at $\mathrm{pH} 3.5$ and the negative ionization mode. The characteristic isotopic distribution of the tin atom allows clear proof of the presence of tin in these fragment ions because element chlorine has two isotopes with the relative isotopic abundance of $\mathrm{m} / \mathrm{z} 35(75.78 \%)$ and $37(24.22 \%)$, while element tin has 10 isotopes with relatively higher abundance isotopes of $\mathrm{m} / \mathrm{z} 116(14.54 \%)$, $118(24.22 \%), 120(32.58 \%), 122(4.63 \%)$ and $124(5.79 \%)$. Comparing the spectra of MMT and the intermediate product, it can be found that there are no spectra at $\mathrm{m} / \mathrm{z}$ 239, 241 and 243, the molecular weight of monomethyltin
A
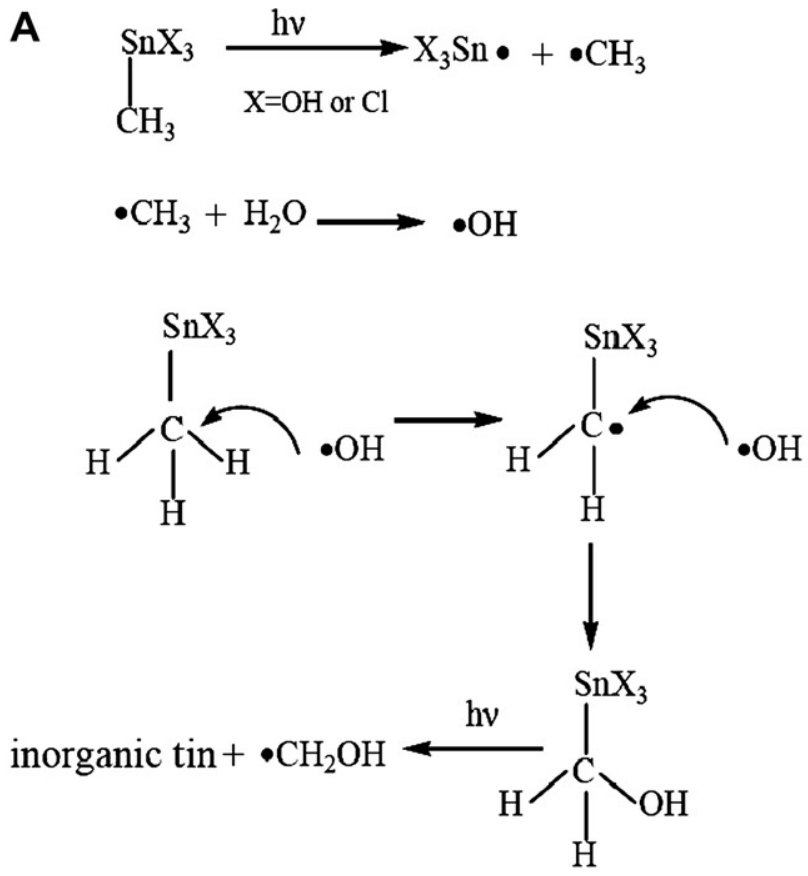<smiles>CC#[C+][Sn](C)(O)[Hg]O[Sn](C)(O)O</smiles>

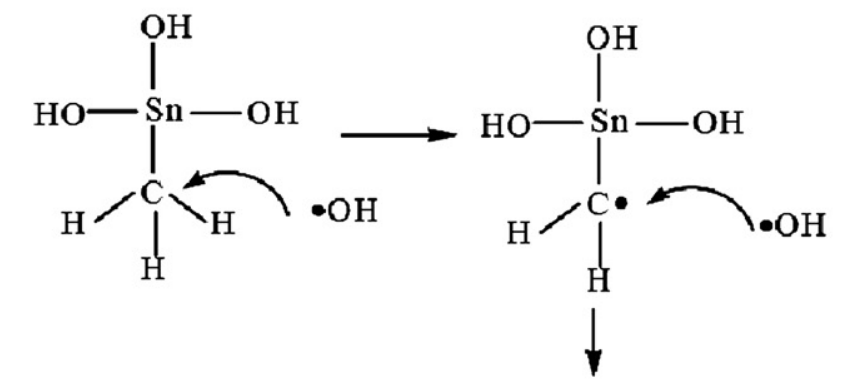

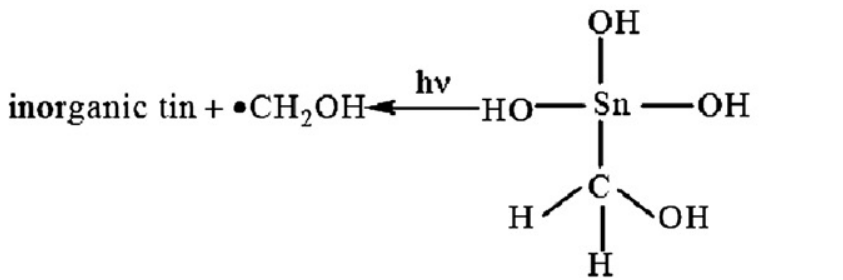

Fig. 5. Possible photodegradation mechanism of MMT: (A) at $\mathrm{pH} 4$ and 6, (B) at $\mathrm{pH} 8$

trichloride $\left(\left[\mathrm{CH}_{3} \mathrm{SnCl}_{3}\right]^{0}\right)$, which is a neutral molecule and can not produce the signal at the negative mode. This is why there are strong signals at $\mathrm{m} / z 273,275,277$ and 279 $\left(\left[\mathrm{CH}_{3} \mathrm{SnCl}_{4}\right]^{-}\right)$. Although the intermediate product and MMT have the same ratio of mass/charge at $\mathrm{m} / \mathrm{z} 273$, 275,277 and 279 , the isotopic intensity of $m / z 275$ is stronger than $\mathrm{m} / z 277$ for MMT than for the intermediate product, suggesting they are different compounds and contain different numbers of chlorine atoms. According to the 
calculation of a series of molecular weights (Table 1), the intermediate product can be concluded to be methyloltin compound $\left(\mathrm{CH}_{2} \mathrm{OH}\right) \mathrm{Sn}^{3+}$ and it is $\left[\mathrm{Sn}\left(\mathrm{CH}_{2} \mathrm{OH}\right)(\mathrm{OH}) \mathrm{Cl}_{3}\right]^{-}$ that give $\mathrm{m} / z$ 273, 275, 277 and 279. In fact, the alcohol derivatives of tributyltin were also found to be the intermediary product in the study of tributyltin photodegradation (Soderquist and Crosby, 1980).

\subsection{Photodegradation mechanism}

As the result of ESI-Q-TOF-MS suggests the intermediate product be methyloltin compound, it is relatively easy to elucidate the possible photodegradation mechanism. MMT produces inorganic tin and methyloltin compound through free hydroxyl radical reaction at $\mathrm{pH} 4$ and 6 . However, the reaction mechanism is different at $\mathrm{pH} 8$ as methyloltin compound is always the major product until the complete degradation of MMT. This is due to the production of the hydroxyl radical that was partly inhibited at $\mathrm{pH}$ 8 and the hydroxyl radical mainly attacks the methyl group to produce the methyloltin compound first, then the hydroxyl radical attack leads to the cleavage of $\mathrm{Sn}-\mathrm{C}$ bond and finally produces the inorganic tin (Fig. 5). DMT has a similar photodegradation pathway to MMT, which produce MMT, methyloltin compound and inorganic tin at $\mathrm{pH} 4$ and 6, as well as the same phenomenon as MMT at $\mathrm{pH} 8$ (figure not shown). TMT has different degradation mechanism from MMT and DMT as almost no methyloltin compound was detected even at $\mathrm{pH} 8$. Therefore, the mechanism for TMT is that more methyl groups were simultaneously demethylated for TMT degradation under the UV irradiation.

\subsection{Effect of salinity on degradation}

The degradation rates of methyltin compounds were strongly affected by the salinity of aqueous solutions (Fig. 6). For TMT and DMT, the degradation rates at pH 6 decreased with the increase of $\mathrm{NaCl}$ concentrations in the range of $0-3.0 \%(\mathrm{~m} / \mathrm{v})$. For MMT, however, the degradation rate in solutions with $\mathrm{NaCl}$ was much higher than that without $\mathrm{NaCl}$, though the degradation rate also decreased with the increase of $\mathrm{NaCl}$ concentrations in the range of $0.5-3.0 \%(\mathrm{~m} / \mathrm{v})$. It is noteworthy that the $\mathrm{NaCl}$
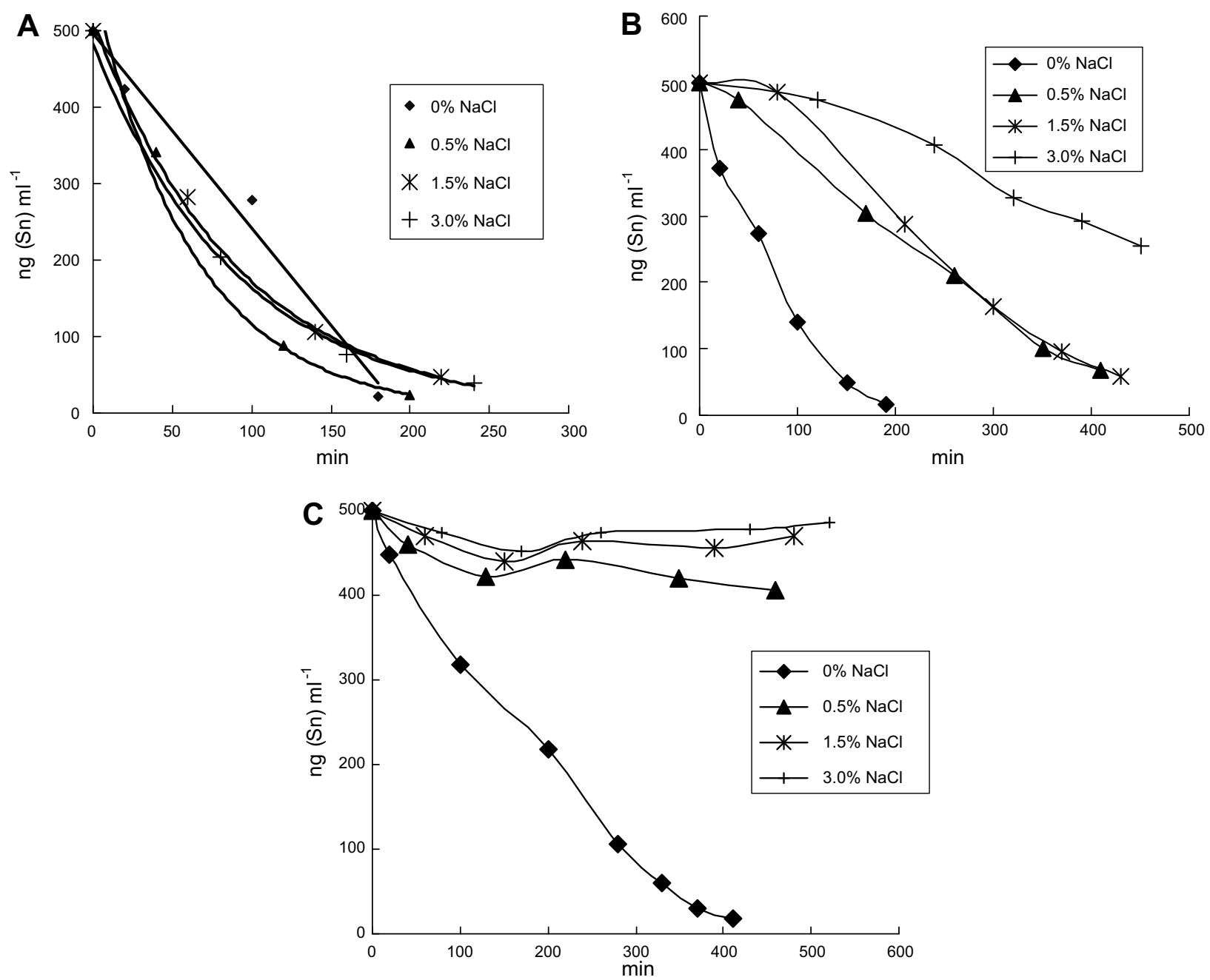

Fig. 6. Effect of salinity on the photodegradation rates of methyltins at pH 6. (A) MMT, (B) DMT, (C) TMT. 
almost completely inhibited the degradation of TMT within $500 \mathrm{~min}$. The degradation rate of DMT is greatly reduced by saline. The half-life times in solutions containing $\mathrm{NaCl}$ are more than twice of those without $\mathrm{NaCl}$, and it increased with the $\mathrm{NaCl}$ concentration in the range of 0.5 $3.0 \%(\mathrm{~m} / \mathrm{v})$. This is because $\mathrm{Cl}^{-}$can scavenge the free radical in solutions of TMT and DMT. Furthermore, TMT was firstly degraded to DMT and then to other products, thus TMT degradation was greatly inhibited with the increase of $\mathrm{NaCl}$ concentration. However, it is difficult to explain the increase of degradation rate for MMT in the solution containing $\mathrm{NaCl}$ in comparison to that without $\mathrm{NaCl}$. It is possible that the chloride anion can form ion pairs with alkyltin(IV) cations and their hydrolysed species, such as the formation of $(\mathrm{CH} 3) \mathrm{Sn}(\mathrm{OH}) \mathrm{Cl}^{+}$and other $\mathrm{Cl}^{-}$ mixed species (Stefano et al., 1999), which greatly decreases the bond energy of C-Sn in MMT and lead to the easier degradation of MMT, even though the scavenger function of chloride ion is taken into account.

\subsection{Effect of humic acid on degradation}

The degradation rates of methyltin compounds were strongly influenced by the humic acid at $\mathrm{pH} 6$ in this study (Fig. 7). It is interesting that the degradation rate of MMT is the zero order at $\mathrm{pH} 6$ and various concentrations humic acid (0-9 mg $\left.\mathrm{l}^{-1}\right)$, and decreased with increasing of humic acid concentration with half-life times of $95,113,180$ and $254 \mathrm{~min}$ at $0,3,6$ and $9 \mathrm{mg}^{-1}$ of humic acid, respectively. While DMT had slight degradation at the range of 0-9 $\mathrm{mg}^{-1}$ of humic acid, TMT was almost completely inhibited by the humic acid (3-9 $\left.\mathrm{mg}^{-1}\right)$ at $\mathrm{pH}$ 6. It is noteworthy that the degradation routes with humic acid are the same as that without humic acid because the same intermediary products were detected. Two major reasons might be responsible for the decrease of methyltin degradation rate by humic acid. First, methyltins can reacts with humic acid to form polymeric species (Omar and Bowen, 1982) as humic acid, a ubiquitous class of electrolytes, can form the complexes with organotin compounds in natural waters through chelation and hydrogen bonding (Oloughlin et al., 2000; Giacalone et al., 2006), which influence strongly the degradation rates of methyltins. For example, Arnold et al. (1998) found that triorganotin cation can form the complexes with negatively charged ligands (i.e., carboxylate and phenolate groups) of the humic acids over the $\mathrm{pH}$ range 5.7-9.3. Second, humic acid and its UV degradation products (Garbin et al., 2007) can bind with free radicals and thus function as a powerful free radical scavenger. However, it is not clear why the degradation rate orders are
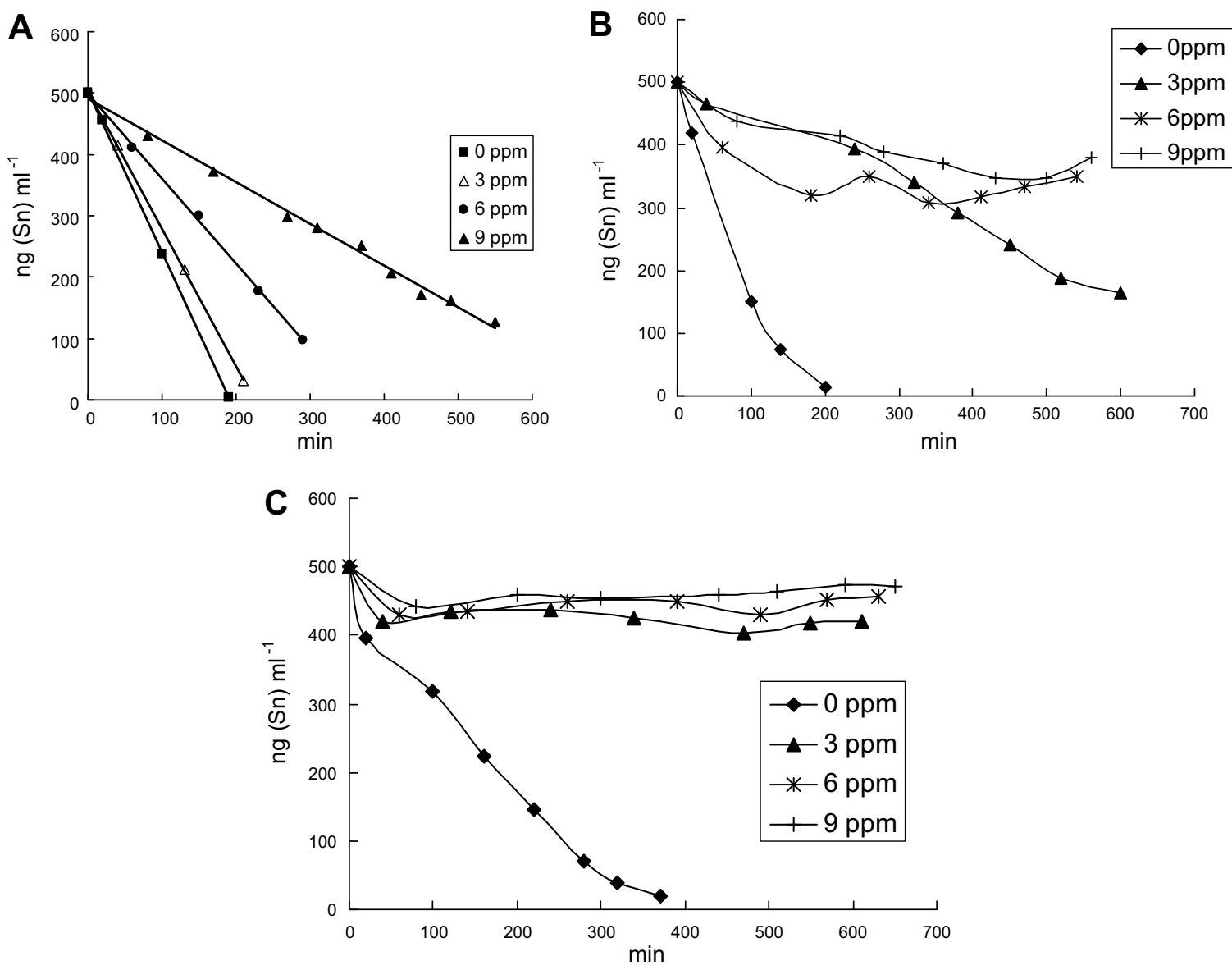

Fig. 7. Effect of humic acid concentration on the photodegradation rates of methyltins at pH 6. (A) MMT, (B) DMT, and (C) TMT. 
different from each other for MMT, DMT and TMT. It may be due to form the different complex structures of methyltins and humic acid.

\section{Conclusion}

The photodegradation of methyltins was systematically studied under different environmental conditions by the application of the newly developed HPLC-FPD hyphenated system. The elucidation of the previously unknown product helps us to better understand the mechanism of the degradation process of methyltin compounds. At the same time, these results can forecast the behavior and fate of methyltins in the environment. It is also important to understand the environmental behavior of other organotin compounds, such as butyltins and phenyltins.

\section{Acknowledgments}

This work was supported by the National Natural Science Foundation of PR China (20577057 and 40503014) and by the State High Tech Development Plan (2006AA06Z424).

\section{Appendix A. Supplementary material}

Supplementary data associated with this article can be found, in the online version, at doi:10.1016/j.chemosphere. 2008.02.048.

\section{References}

Allen, D.W., Brooks, J.S., Unwin, J., McGuinness, J.D., 1987. Studies of the degradation of organotin stabilizers in poly(vinyl chloride) during gamma irradiation. Appl. Organomet. Chem. 1, 311-317.

Arnold, C.G., Ciani, A., Muller, S.R., Mirbahman, A., Schwarzenbach, R.P., 1998. Association of triorganotin compounds with dissolved humic acids. Environ. Sci. Technol. 32, 2976-2983.

Apek, M.H., Kolarova, L., Ruzicka, A., Jambor, R., Jandera, P., 2006. Structural analysis of ionic organotin(IV) compounds using electrospray tandem mass spectrometry. Anal. Chem. 78, 4210-4218.

Ashby, J.R., Craig, P.J., 1988. Environmental methylation of tin: an assessment. Sci. Total Environ. 73, 127-133.

Aue, W.A., Flinn, C.G., 1977. A photometric tin detector for gas chromatography. J. Chromatogr. 142, 145-154.

Blunden, S.J., 1983. The ultraviolet degradation of the methyltin chlorides in carbon tetrachloride and water. J. Organomet. Chem. 248, 149-160.

Burton, E.D., Phillips, I.R., Hawker, D.W., 2005. In-situ partitioning of butyltin compounds in estuarine sediments. Chemosphere 59, 585-592.

Burton, E.D., Phillips, I.R., Hawker, D.W., 2006. Tributyltin partitioning in sediments: effect of aging. Chemosphere 63, 73-81.

Chao, W., Jiang, S., 1998. Determination of organotin compounds by liquid chromatography inductively coupled plasma mass spectrometry with a direct injection nebulizer. J. Anal. At. Spectrom. 13, 1337-1341.

Dagnall, R.M., Thompson, K.C., West, T.S., 1968. Molecular-emission spectroscopy in cool flames part III. The emission characteristics of tin in diffusion flames. Analyst 93, 518-521.

Ebdon, L., Hill, S.J., Rivas, C., 1998. Organotin compounds in solid waste: a review of their properties and determination using highperformance liquid chromatography. Trends Anal. Chem. 17, 277-287.

Fent, K., 1996. Ecotoxicology of organotin compounds. Crit. Rev. Toxicol. 26, 1-117.
Garbin, J.R., Milori, D.M.B.P., Simões, M.L., da Silva, W.T.L., Neto, L.M., 2007. Influence of humic substances on the photolysis of aqueous pesticide residues. Chemosphere 66, 1692-1698.

Giacalone, A., Gianguzza, A., Pettignano, A., Sammartano, S., 2006. Sequestration of organometallic compounds by natural organic matter: binding of trimethyltin(IV) by fulvic and alginic acids. Appl. Organomet. Chem. 20, 706-717.

Gómez-Ariza, J.L., Santos, M.M., Morales, E., Giráldez, I., SánchezRodas, D., Vieira, N., Kemp, J.F., Boon, J.P., Ten-Hallers-Tjabbes, C.C., 2006. Organotin contamination in the Atlantic Ocean off the Iberian Peninsula in relation to shipping. Chemosphere 64, 1100-1108.

Harinoa, H., Fukushimaa, M., Kurokawab, Y., Kawai, S., 1997. Susceptibility of bacterial populations to organotin compounds and microbial degradation of organotin compounds in environmental water. Environ. Pollut. 98, 157-162.

Henderson, W., Taylor, M.J., 1996. Organotin halides and their hydrolysed species studied in solution by positive and negative ion electrospray mass spectrometry. Polyhedron 15, 1957-1964.

Inoue, H., Takimura, O., Fuse, H., Murakami, K., Kamimura, K., Yamaoka, Y., 2000. Degradation of triphenyltin by a fluorescent pseudomonad. Appl. Environ. Microbiol. 66, 3492-3498.

Lee, C.-C., Hsieh, C.-Y., Tien, C.-J., 2006. Factors influencing organotin distribution in different marine environmental compartments, and their potential health risk. Chemosphere 65, 547-559.

Liang, C., Wang, Z., Bruell, C.J., 2007. Influence of $\mathrm{pH}$ on persulfate oxidation of TCE at ambient temperatures. Chemosphere 66, 106-113.

Lipczynska-Kochany, E., Sprah, G., Harms, S., 1995. Influence of some groundwater and surface waters constituents on the degradation of 4chlorophenol by the Fenton reaction. Chemosphere 30, 9-20.

Maguire, R.J., Carey, J.H., Hale, E.J., 1983. Degradation of the tri-nbutyltin species in water. J. Agric. Food Chem. 31, 1060-1065.

Mailhot, G., Astruc, M., Bolte, M., 1999. Degradation of tributyltin chloride in water photoinduced by iron(III). Appl. Organomet. Chem. 13, 53-61.

Morabito, R., Massanisso, P., 2000. Derivatization methods for the determination of organotin compounds in environmental samples. Trends Anal. Chem. 19, 113-119.

Marugan, J., Hufschmidt, D., Lopez-Munoz, M., Selzer, V., Bahnemann, D., 2006. Photonic efficiency for methanol photooxidation and hydroxyl radical generation on silica-supported $\mathrm{TiO}_{2}$ photocatalysts. Appl. Catal. B-Environ. 62, 201-207.

Navio, J.A., Cerrillos, C., Marchena, F.J., Pablos, F., Pradera, M.A., 1996. Photoassisted degradation of $n$-butyltin chlorides in air-equilibrated aqueous $\mathrm{TiO}_{2}$ suspension. Langmuir 12, 2007-2014.

Oloughlin, E.J., Traina, S.J., Chin, Y., 2000. Association of organotin compounds with aquatic and terrestrial humic substances. Environ. Toxicol. Chem. 19, 2015-2021.

Omar, M., Bowen, H.J.M., 1982. Separation of methyltin species from inorganic tin and their interactions with humates in natural waters. J. Radioanal. Nucl. Chem. 74, 273-282.

Pellegrino, C., Massanisso, P., Morabito, R., 2000. Comparison of twelve selected extraction methods for the determination of butyl- and phenyltin compounds in mussel samples. Trends Anal. Chem. 19, 97 106.

Pettibone, G.W., Cooney, J.J., 1988. Toxicity of methyltins to microbial populations in estuarine sediments. J. Ind. Microbiol. Biotechnol. 2, 373-378.

Ritsema, R., 1992. Speeiation of organotin and organoarsenie in water samples. Mikrochim. Acta 109, 61-65.

Rosenberg, E., Kmetov, V., Grasserbauer, M., 2000. Investigating the potential of high-performance liquid chromatography with atmospheric pressure chemical ionization-mass spectrometry as an alternative method for the speciation analysis of organotin compounds. Fresenius J. Anal. Chem. 366, 400-407.

Rosenberg, E., 2003. The potential of organic (electrospray- and atmospheric pressure chemical ionisation) mass spectrometric techniques coupled to liquid-phase separation for speciation analysis. J. Chromatogr. A 1000, 841-889. 
Rüdel, H., Müller, J., Steinhanses, J., Schröter-Kermani, C., 2007. Retrospective monitoring of organotin compounds in freshwater fish from 1988 to 2003: results from the German environmental specimen bank. Chemosphere 66, 1884-1894.

Soderquist, C.J., Crosby, D.G., 1980. Degradation of triphenyltin hydroxide in water. J. Agric. Food Chem. 28, 111-117.

Soderquist, C.J., Crosby, D.G., 1978. Determination of triphenyltin hydroxide and its degradation products in water. Anal. Chem. 50, $1435-1439$.

Stefano, C.D., Foti, C., Gianguzza, A., Marrone, F., Sammartano, S., 1999. Hydrolysis of methyltin(IV) trichloride in aqueous $\mathrm{NaCl}$ and
$\mathrm{NaNO}_{3}$ solutions at different ionic strengths and temperatures. Appl. Organomet. Chem. 13, 805-811.

Tao, H., Rajendran, R.B., Quetel, C.R., Nakazato, T., Tominaga, M., Miyazaki, A., 1999. Tin speciation in the femtogram range in open ocean seawater by gas chromatography/inductively coupled plasma mass spectrometry using a shield torch at normal plasma conditions. Anal. Chem. 71, 4208-4215.

Zhai, G., Liu, J., Jiang, G., He, B., Zhou, Q., 2007. On line coupling HPLC and quartz surface-induced luminescence FPD with hydride generation and microporous membrane gas-liquid separator as interface for the speciation of methyltins. J. Anal. At. Spectrom. 22, 1420-1426. 